\title{
Uma análise do emprego formal nos setores industrial e de serviços brasileiros
}

\section{Introdução}

Luciano Nakabashi*

Fábio Dória Scatolin ${ }^{* *}$

Márcio José V argas da Cruz.**

Gabriel Porcile ${ }^{* * * *}$

Considerando o fenômeno da desindustrialização como a perda persistente de participação da indústria no emprego de um país, alguns estudos já detectaram a sua existência no Brasil, como aqueles realizados por Feijó et al. (2005) em um relatório preparado para o Instituto de Estudos para o Desenvolvimento Industrial (IEDI) e por Scatolin et al. (2007), além da presença do mesmo fenômeno em outros países da América Latina (Palma, 2005).

Esse processo não tem, em princípio, nenhuma implicação positiva ou negativa para o bem-estar. Suas implicações dependem do que acontece com o emprego e a produtividade tanto na indústria como nos outros setores da economia. Se a perda de empregos industriais resulta dos ganhos de produtividade no setor e, além disso, tem como contrapartida a geração de empregos de produtividade elevada em outros setores, principalmente em serviços ligados às novas tecnologias, então as mudanças são o resultado natural da dinâmica do progresso técnico e tendem a contribuir com o processo de desenvolvimento econômico.

Argumenta-se, no entanto, que no caso brasileiro, assim como em outros países da América Latina, a desindustrialização tem outras causas. Por um lado, a produtividade na indústria brasileira tem aumentado menos do que nas economias desenvolvidas. Por outro lado, existem evidências de que ela tem sido acompanhada pela criação de empregos de baixa produtividade no setor terciário. Nas duas situações, a perda de participação da indústria acaba por gerar um menor dinamismo da economia brasileira como um todo.

\footnotetext{
* Doutor em Economia pelo CEDEPLAR/UFMG. Professor do Departamento de Economia da Universidade Federal do Paraná (UFPR). Endereço eletrônico: luciano.nakabashi@ufpr.br

** Doutor em Economia pela University of London. Professor do Departamento de Economia da Universidade Federal do Paraná (UFPR). Endereço eletrônico: scatolin@ufpr.br

*** Mestre em Economia pela Universidade Federal do Paraná. Professor do Departamento de Economia da Universidade Federal do Paraná (UFPR). Endereço eletrônico: marciocruz@,ufpr.br

**** Doutor em História Econômica pela London School of Economics. Professor do Departamento de Economia da Universidade Federal do Paraná (UFPR) e Pesquisador do CNPq. Endereço eletrônico: porcile@,uol.com.br
} 
O presente artigo centra a análise nesse segundo fenômeno, ou seja, no destino dos empregos que estariam sendo gerados na indústria caso ela mantivesse a mesma participação no total do emprego da economia.

\section{Evidências e causas do processo de desindustrialização}

Rowhtorn e Ramaswamy (1997) realizaram um estudo empírico mostrando que o processo de desindustrialização que ocorre nos países avançados é uma conseqüência natural do dinamismo industrial daqueles países. Seus determinantes estão relacionados ao aumento de produtividade, e não à perda de competitividade da indústria. Quando a desindustrialização se explica em grande medida pelo dinamismo da produtividade, ela se associa ao aumento do emprego de alta produtividade e elevada qualificação da mão-de-obra em outros setores da economia. Trata-se de um processo virtuoso, natural, de mudança estrutural no desenvolvimento de uma economia (Rowhtorn e Ramaswamy, 1999).

Segundo Palma (2005) esse não é o caso dos países da América Latina. Ele observa que alguns países da América Latina como Brasil, Argentina, Chile e Uruguai, por razões diferentes dos países avançados, começaram a passar por um processo de desindustrialização rápida nos anos oitenta, apesar de suas rendas per capita serem muito mais baixas que a dos países avançados no momento em que esses últimos começaram um processo similar. Esta especificidade latino-americana teria mais relações de causa e efeito com a política macroeconômica do período do que com os determinantes da desindustrialização nos países avançados. Devido a essas especificidades, esse grupo de países estaria passando por uma desindustrialização precoce, fruto da debilidade de sua base industrial e tecnológica.

Palma (2005) sugere que esse fenômeno estaria se aprofundando devido a uma súbita mudança na política econômica, em particular a rápida liberalização comercial e financeira, o fim das políticas industriais e comerciais.

Considerando um período mais recente, Scatolin et al. (2007), Mendonça de Barros (2006) e Nakano (2005) ressaltam que a valorização cambial que teve início no final de 2002 como conseqüência da elevada demanda internacional por algumas commodities, tem influenciado negativamente o setor industrial do país. 


\section{Análise empírica}

\subsection{Indústria}

O gráfico 1 evidencia a perda de participação do emprego formal na indústria, sendo que a maior parte do emprego que deveria estar sendo gerado nesse setor acaba migrando para as vagas que surgem no setor de serviços:

Gráfico 1. Estoque de emprego formal nos setores de serviços e indústria (1985-2005)

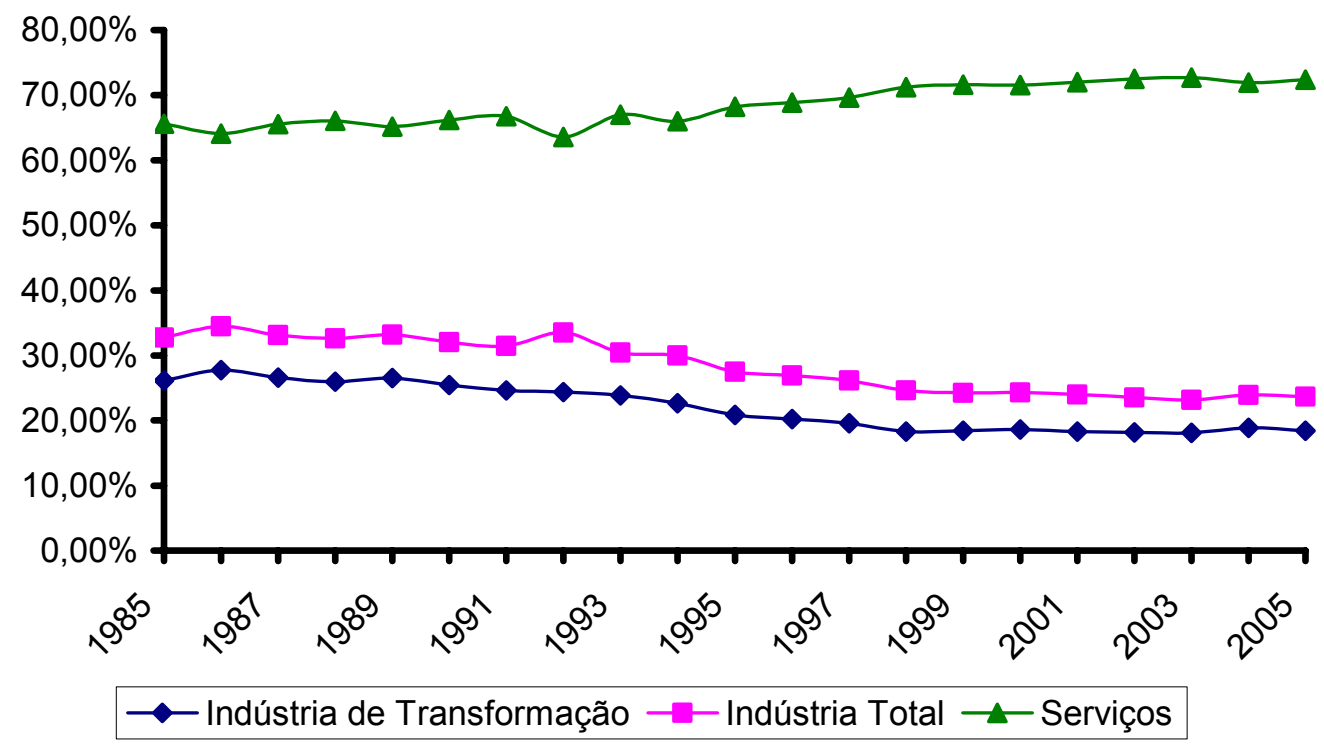

Fonte: Elaboração própria a partir de dados do Ministério do Emprego e Trabalho (RAIS)

Observa-se que tanto a indústria de transformação quanto a indústria como um todo vem perdendo participação no total de emprego. Como a indústria de transformação é um dos segmentos que tem maior importância no dinamismo da economia, seria de se esperar que a sua perda de importância relativa também tivesse impactos negativos sobre o desempenho da economia como um todo.

Cabe lembrar, como enfatizado por Hirschman (1958), que a indústria tem um maior potencial de gerar efeitos positivos sobre a economia. O segmento da indústria de transformação, por ser ainda mais dinâmico, teria maiores efeitos sobre o desempenho da economia como um todo.

Alguns autores, através de estudos empíricos, também encontram evidências da existência de importantes efeitos de encadeamento no setor industrial, como o realizado por Hanson (1998) para a economia mexicana e por Glaeser et al. (1992), em um estudo utilizando 170 cidades americanas.

Dividindo a indústria de transformação em quatro segmentos: 1) baseados em recursos naturais; 2) baixa tecnologia; 3) média tecnologia; e 4) alta tecnologia (gráfico 2), é 
possível observar que, além dela ter perdido participação no total de emprego da economia, como apresentado no gráfico 1 , o segmento que mais perdeu participação foi o de média tecnologia.

Gráfico 2. Os segmentos da indústria de transformação de acordo com o grau de intensidade tecnológica (1985-2005)

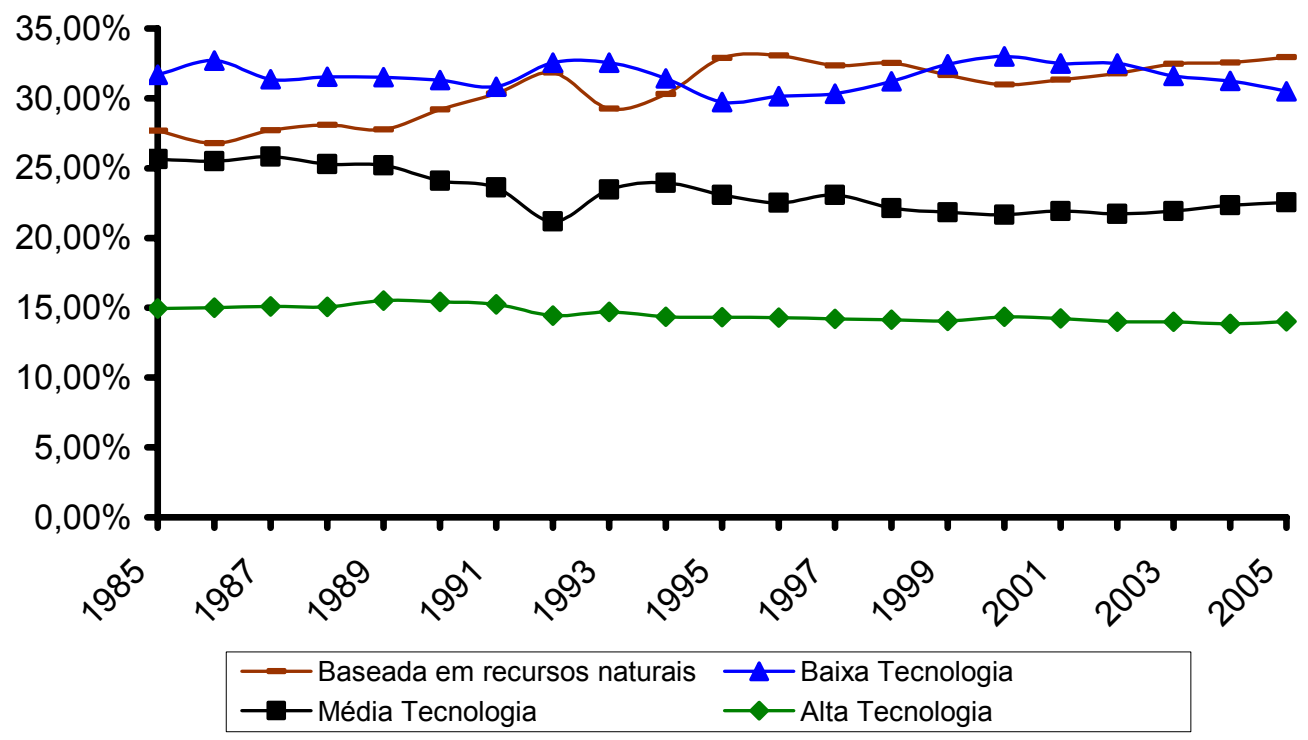

Fonte: Elaboração própria a partir de dados do Ministério do Emprego e Trabalho (RAIS)

A evidência empírica que mais chama a atenção no gráfico 2 é o fato de que o único segmento da indústria de transformação que ganhou participação no emprego total, considerando o período 1985-2005, foi o baseado em recursos naturais. No entanto, considerando o emprego total da economia, o segmento da indústria de transformação baseado em recursos naturais também perdeu participação no período, passando de 7,25\% para $6,08 \%$.

O Ministério do Emprego e Trabalho disponibiliza os dados de emprego formal através da divisão da indústria de transformação em doze segmentos ${ }^{7}$. Destes, apenas um apresentou ganho de participação no emprego total da economia entre 1985-2005: o segmento de indústria de produtos alimentícios, bebidas e álcool etílico cuja participação passou de 4,07\%, em 1985, para 4,23\%, em 2005.

\footnotetext{
${ }^{7}$ Baseado em recursos naturais: 1) Indústria do Papel, Papelão, Editorial e Gráfica; 2) Ind. da Borracha, Fumo, Couros, Peles, Similares, Ind. Diversas; e 3) Indústria de Produtos Alimentícios, Bebidas e álcool Etílico. Baixa Tecnologia: 4) Indústria de Produtos Minerais não Metálicos; 5) Indústria da Madeira e do Mobiliário; 6) Indústria Têxtil do Vestuário e Artefatos de Tecidos; e 7) Indústria de Calçados. Média Tecnologia: 8) Indústria Metalúrgica; 9) Indústria Mecânica; e 10) Indústria do Material de Transporte. Alta Tecnologia: 11) Indústria do Material Elétrico e de Comunicações; e 12) Ind. Química de Produtos Farmacêuticos, Veterinários, Perfumaria,...
} 
Essas evidências dão suporte ao argumento de Palma (2005) de que a desindustrialização que está ocorrendo nos países da América Latina não se trata de um processo virtuoso, pois os segmentos da indústria que mais perdem participação são os mais dinâmicos.

\subsection{Serviços}

No caso brasileiro a desagregação da RAIS nos dá uma idéia do que está ocorrendo com o nível de emprego formal no setor de serviços, que ampliou sua participação no total de empregos da economia de 65,59\%, em 1985, para 72,39\%, em 2005, com a criação líquida de quase 11 milhões de novos empregos.

De todos os segmentos do setor de serviços o que mais se expandiu em termos absolutos de geração de empregos foi o da Administração Pública, com um crescimento, em termos absolutos, de 3.146 mil empregos entre 1985 e 2005 (gráfico 3). No entanto sua participação no total de empregos do setor se reduziu de 33,65\% para 31,35\%, no mesmo período (gráfico 4).

O segmento que absorveu o segundo maior contingente foi o comércio varejista com um ganho líquido de 2.934 mil empregos no período (gráfico 3). Adicionalmente, foi o segmento do setor de serviços que mais aumentou sua participação relativa, passando de 16,21\% para 21\% no total desse setor, no período 1985-2005 (gráfico 4).

Gráfico 3. Estoque de emprego formal nos segmentos do setor de serviços (1985-2005)

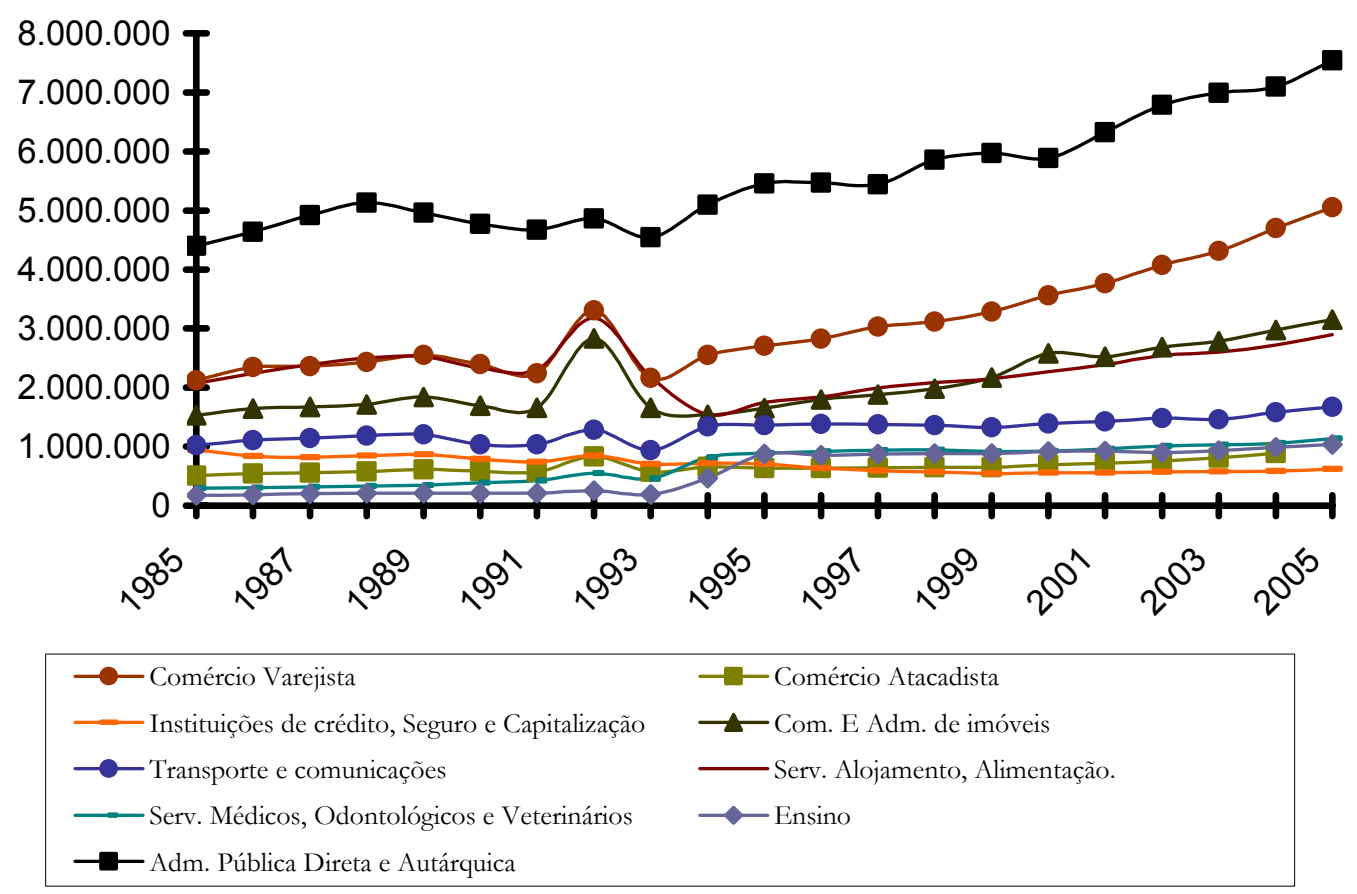

Fonte: Elaboração própria a partir de dados do Ministério do Emprego e Trabalho (RAIS) 
O segmento de comércio e administração de imóveis, valores mobiliários e serviço técnico também teve destaque na geração de emprego no período analisado (1.620 mil novos empregos). Conforme pode ser visto no gráfico 4, sua participação no total de empregos formais do setor de serviços passou de 11,71\% para 13,09\% entre 1985 e 2005.

Dois outros setores de destaque na geração de emprego formal foram o de ensino e de serviços médicos, odontológicos e veterinários. Em termos absolutos os dois segmentos, conjuntamente, geraram 1.663 mil novos empregos entre 1985 e 2005, com um grande salto nos anos de 1995 e 1994, respectivamente, como se pode observar no gráfico 3. Em termos de participação relativa no emprego formal total do setor de serviços, os dois ganharam uma fatia de 5,4\%, no período em questão (gráfico 4).

Gráfico 4. Participação no emprego formal de cada segmento do setor de serviços no estoque de emprego formal desse setor (1985-2005)

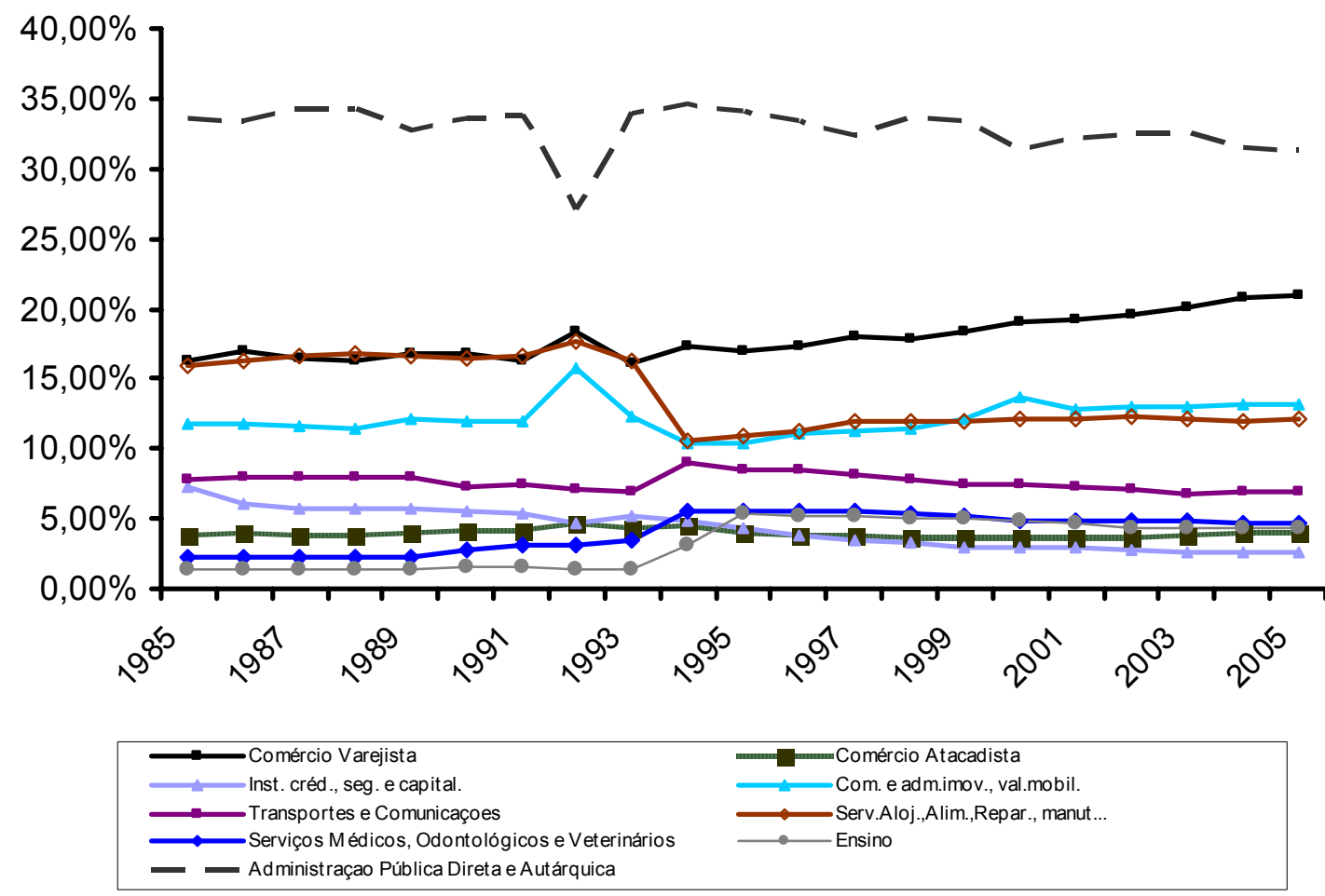

Fonte: Elaboração própria a partir de dados do Ministério do Emprego e Trabalho (RAIS)

Com o processo natural de desindustrialização que ocorre nos países, é fundamental que ocorra o desenvolvimento do setor de serviços de tal forma que esse passe a desempenhar um papel dinâmico como motor alternativo de crescimento. Ou seja, é importante que seu desenvolvimento ocorra, principalmente, em segmentos que exijam uma alta qualificação e que sejam relacionados a atividades consideradas de alta tecnologia. 
Por exemplo, Dasgupta e Singh (2006) encontraram resultados que indicam que o setor industrial na Índia continua a ter um papel importante no desenvolvimento econômico como preconizado por Kaldor (1957). No entanto, eles também encontraram evidências de que, atualmente, o setor de serviços está ganhando importância como um motor alternativo de crescimento econômico. Em outro estudo empírico para a economia indiana, Dasgupta e Singh (2005) encontraram que os segmentos do setor de serviços que mais ganham importância como um motor alternativo do crescimento são aqueles ligados à tecnologia de informação e comunicação.

No entanto, no caso brasileiro, o que se percebe pela análise dos gráficos 3 e 4 é que alguns segmentos do setor de serviços que possuem um baixo e médio dinamismo tecnológico são justamente aqueles que mais geraram emprego. Assim, o emprego que deixa de ser criado no setor industrial está migrando para os segmentos do setor de serviço de baixa e média intensidade tecnológica e que não exigem um elevado nível de qualificação. Portanto, o potencial que esses segmentos possuem em gerar um dinamismo econômico é baixo.

O segmento do setor de serviços ligado a transportes e comunicações brasileiros que é o que mais se aproxima dos segmentos relacionados à tecnologia de informação e comunicação que têm ganhado espaço na Índia - mesmo tendo gerado cerca de 650 mil empregos entre 1985 e 2005, perdeu participação relativa no total de empregos do setor de serviços, passando de 7,81\% para 6,95\%, no mesmo período ${ }^{8}$.

Para se ter uma melhor idéia de tal fenômeno podemos separar o setor de serviços em três segmentos: 1) de baixas qualificação e intensidade tecnológica; 2) médias qualificação e intensidade tecnológica; e 3) alta qualificação e intensidade tecnológica ${ }^{9}$. Este seria o segmento do setor de serviços que teria a possibilidade de substituir a indústria como um motor de dinamismo da economia como um todo, de acordo com o estudo realizado por Dasgupta e Singh (2005). Os resultados são apresentados no gráfico 5:

\footnotetext{
${ }^{8}$ Mesmo considerando o nível total de emprego na economia, a participação do segmento do setor de serviço ligado a transportes e comunicações perdeu participação, passando de 5,12\% para 5,03\%, no período em questão.

9 Segmento de baixas qualificação e intensidade tecnológica: 1) comércio varejista; 2) comércio atacadista; 3) comércio e administração de imóveis, valores mobiliários, serviço técnico; 4) serviço de alojamento, alimentação, reparação, manutenção, redação; 5) administração pública direta e autárquica. Segmento de médias qualificação e intensidade tecnológica: 6) serviços médicos, odontológicos e veterinários; 7) ensino. Segmento de altas qualificação e intensidade tecnológica: 8) instituições de crédito, seguros e capitalização; 9) transportes e comunicações.
} 
Gráfico 5. Os segmentos do setor de serviços de acordo com o grau de intensidade tecnológica (1985-2005)

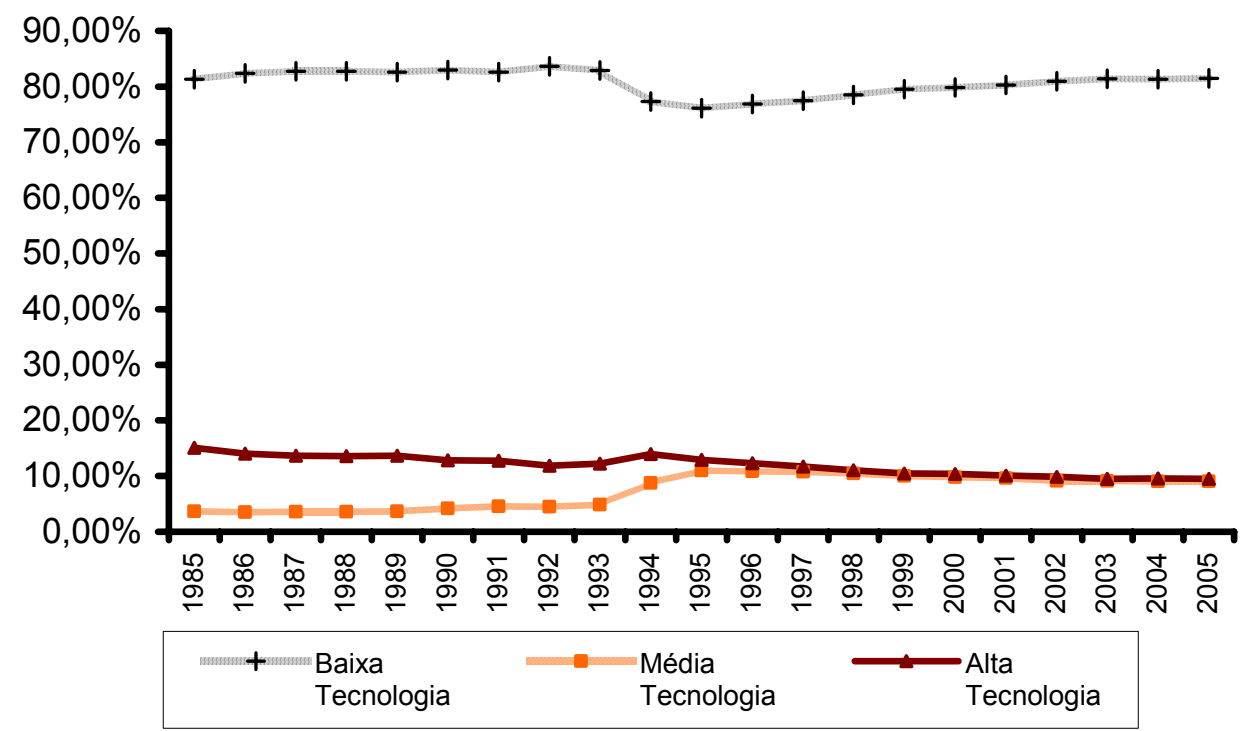

Fonte: Elaboração própria a partir de dados do Ministério do Emprego e Trabalho (RAIS)

Pelos resultados do gráfico 5, pode-se observar uma clara tendência de ganho relativo do emprego no segmento do setor de serviços baseado em média tecnologia sendo compensado por uma perda de importância relativa do emprego do segmento do setor de serviços baseado em alta tecnologia. Portanto, aquele segmento do setor de serviços que poderia substituir a indústria como um motor de dinamismo da economia como um todo também está perdendo participação relativa no emprego formal.

Assim, a perda de participação relativa tanto dos segmentos do setor de serviços que são mais dinâmicos, bem como dos segmentos da indústria de transformação que são mais intensivos em tecnologia, sendo esse último efeito aprofundado pela perda da participação do emprego da indústria de transformação no emprego total da economia, resultam em um foco de preocupação frente às perspectivas de crescimento econômico de longo prazo da economia brasileira. Além disso, esta dinâmica pode corroborar com o entendimento dos motivos que levaram e levam ao baixo desempenho econômico brasileiro a partir da década de 80 até os dias atuais.

\section{Considerações finais}

Como já detectado em alguns estudos empíricos, como aqueles realizados por Feijó et al. (2005) e por Scatolin et al. (2007), o país está passando por um processo de desindustrialização que se iniciou nos anos 80 . 
Se tal fenômeno estivesse ocorrendo concomitantemente ao ganho de participação nos segmentos do setor de serviços que possuem grande potencial dinâmico e de efeitos de encadeamento com outros setores da economia, tal processo seria natural e virtuoso, como destacado por Rowthorn e Ramaswamy (1999) em um estudo para os países desenvolvidos. Outro exemplo é o caso da Índia, no estudo realizado por Dasgupta e Singh (2005), onde os autores encontraram evidências de que os segmentos do setor de serviços que mais ganharam importância como um motor alternativo do crescimento da economia indiana são aqueles ligados à tecnologia de informação e comunicação.

No entanto, no caso brasileiro, além da perda de participação do emprego formal na industrial de transformação estar concentrada em seus segmentos mais dinâmicos e de maior conteúdo tecnológico, os segmentos do setor de serviços que mais criaram emprego foram os de média e baixa tecnologia, com uma perda significativa da participação no emprego dos segmentos mais dinâmicos.

A conclusão é que os setores mais dinâmicos da economia brasileira vêm perdendo espaço no que concerne o nível de empregos formais, enquanto que os empregos gerados no setor de serviços não estão concentrados em segmentos com potencial de dinamizar o desempenho da economia como um todo. Assim, o presente estudo traz indícios de que o processo de desindustrialização pelo qual o país vem passando desde meados dos anos 80 é negativo no sentido de prejudicar o processo de desenvolvimento econômico brasileiro.

\section{Referências bibliográficas}

Dasgupta, S.; Singh, A. (2006). Manufacturing, Services and Premature Deindustrialization in Developing Countries, A Kaldorian Analysis. United Nations University Research Paper, 2006/49: 119.

Dasgupta, S.; Singh, A. (2005). Will Services Be the New Engine of Indian Economic Growth? Development and Change, 36 (06): 1035-58.

Feijó, C. A. Carvalho, P.G.M.; Almeida, J.S.G. (2005). Ocorreu uma desindustrialização no Brasil? Texto de Discussão - Instituto de Estudos para o Desenvolvimento Industrial. Disponível em www.iedi.org.br, em 10 de junho de 2006.

Glaeser, E.L.; Kallal, H.D.; Scheinkman, J.A.; Shleifer, A. (1992). Growth in Cities. Journal of Political Economy, 100 (6): 1126-1152.

Hanson, G.H. (1998). Regional Adjustment to Trade Liberalization. Regional Science and Urban economics, 28 (4): 419-444.

Hirschman, A. O. (1958). The strategy of economic development. New Haven:Yale University Press. 

$591-624$.

Kaldor, N. (1957). A Model of Economic Growth. The Economic Journal, 67 (268):

Mendonça De Barros, L.C. A doença chama-se hemocromatose. Folba de São Paulo. 11/08/2006. 2006.

Nakano, Y. Crescimento Econômico. O Estado de São Paulo. 20/09/2005, 2005.

Palma G. (2005). Quatro fontes de desindustrialização e um novo conceito de Doença Holandesa. Trabalho apresentado na Conferência de Industrialização, Desindustrialização e Desenvolvimento, FIESP e IEDI. Centro Cultural da FIESP, 28 de Agosto de 2005.

Rowhtorn R.; Ramaswamy. R. Deindustrialization Causes and Implications. International Monetary Fund Working Paper n. 42, 1997.

Rowhtorn R.; Ramaswamy, R. Growth, Trade, and Deindustrialization. International Monetary Fund (IMF) Staff Papers, vol. 46, n. 1: 18-41, 1999.

Scatolin, F.D.; Cruz, M.J.V.; Porcile, G.; Nakabashi, L. (2007). Desindustrialização? Uma análise comparativa entre Brasil e Paraná. Indicadores Econômicos da FEE, no prelo. 